\title{
Modelling climate change impacts on mycotoxin contamination
}

\author{
H.J. Van der Fels-Klerx ${ }^{1 *}$, C. Liu ${ }^{1}$ and P. Battilani ${ }^{2 *}$ \\ ${ }^{1}$ RIKILT Wageningen University E Research, Akkermaalsbos 2, 6708 WB Wageningen, the Netherlands; ${ }^{2}$ Department \\ of Sustainable Crop Production, Università Cattolica del Sacro Cuore, via Emilia Parmense 84, 29122 Piacenza, Italy; \\ ine.vanderfels@wur.nl, paola.battilani@unicatt.it
}

Received: 16 March 2016 / Accepted: 22 August 2016

(c) 2016 Wageningen Academic Publishers

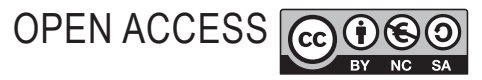

REVIEW ARTICLE

\begin{abstract}
Projected climate change effects will influence primary agricultural systems and thus food security, directly via impacts on yields, and indirectly via impacts on its safety, with mycotoxins considered as crucial hazards. Mycotoxins are produced by a wide variety of fungal species, each having their own characteristics and requirements. The geographic distribution of toxigenic fungi reflects their ecological needs, with thermophilic fungi prevalent at lower latitudes and psychrophiles at the higher latitudes. A resulting gradient of mycotoxin contamination has been repeatedly stressed. Changes in climatic conditions will lead to shifts in the fungal population and the mycotoxin patterns. In general, climate change is expected to increase mycotoxin contamination of crops, but due to the complexity of mycoflora associated to each crop and its interaction with the environment, it appears rash to draw conclusions without specific studies. Very recently first quantitative estimations of impacts of climate change on mycotoxin occurrence have been made. Two studies each applied models of different disciplines including climate projection, crop phenology and fungal/mycotoxin prediction to cereals cultivated in Europe. They were followed by a case study on climate change effects on Alternaria moulds and their mycotoxins in tomato. Results showed that DON contamination of wheat grown in Europe was, in general, expected to increase. However, variation was large, and in some years and some regions a decrease in DON contamination was expected. Regarding aflatoxin contamination of maize grown in Europe, an increase was estimated, mainly in the $+2{ }^{\circ} \mathrm{C}$ scenario. Two main research gaps were identified related to the (limited) number of existing quantitative models taking into account climate change and their validation in limited areas. Efforts are therefore mandatory to be prepared for future changes and challenges on model validation and limited mycotoxin-crop combinations.
\end{abstract}

Keywords: food safety, predictive modelling, Europe, scenario analyses, impact assessment

\section{Introduction}

Projected climate change effects undoubtedly will influence primary agricultural systems, including animal and plant production, and thus food availability. Climate change will affect food security directly via impacts on yields, but also indirectly via impacts on the safety of the available food (Gregory et al., 2005; Liu et al., 2015; Marvin et al., 2013; Tirado et al., 2010; Wheeler and Von Braun, 2013). In addressing food security in relation to our future climate, food safety should, therefore, be considered. Mycotoxins are mentioned to be one of the most important food safety hazards affected by climate change (Miraglia et al., 2008).
Projected climate change effects include an increase in average global air temperatures and changes of precipitation distribution but, particularly, an increase in the variability of the weather with more extreme events such as heat waves, droughts and extreme precipitation (Field, 2012; IPCC, 2007; Pachauri and Reisinger, 2007). Both the foreseen gradual changes and extreme weather events are expected to influence primary agricultural production systems. Depending on the region, climate change effects will either positively or negatively influence crop yields and suitability of land to cultivate particular crops (Liu et al., 2013). However, for most of the globe, climate change is expected to negatively affect agricultural production (Pachauri and Reisinger, 2007). In a model study, climate 
change was estimated to reduce agricultural production in semi-arid (food-insecure) regions of the world (Lobell et al., 2008). Model studies for Europe showed yield variability will increase (Bindi and Olesen, 2011; Ewert et al., 2005; Falloon and Betts, 2010; Olesen et al., 2007). Furthermore, risk of crop failure is expected to increase in Europe (EC, 2009).

In addition to crop production, climate change will also affect the prevalence of fungal species that can infect the crop, associated plant diseases and mycotoxin contamination (Gregory et al., 2009; Madgwick et al., 2011). For instance, following a heat wave in northern Italy in 2003, maize cultivated in this area was highly contaminated with aflatoxins, produced by the fungus Aspergillus flavus. Cows that had consumed the contaminated maize produced milk that was contaminated with aflatoxin $\mathrm{M}_{1}$ (Giorni et al., 2007). Insect outbreaks, which are expected to increase in frequency and to move northwards due to climate change, may cause damage to plants and/or may distribute disease vectors (FAO, 2008a,b; Trnka et al., 2007). These outbreaks are foreseen to result into decreased yields and increased kernel damage, which may result in higher probability of fungal infection and mycotoxin presence.

Although literature reviews on the expected impact from climate change on mycotoxin contamination of cereals and other crops are available (Magan et al., 2011; Marín et al., 2013; Marroquín-Cardona et al., 2014; Medina et al., 2014a,b; Miraglia et al., 2009; Ongoma, 2013; Paterson and Lima, 2010, 2011; Paterson et al., 2014; Tirado et al., 2010; Wu et al., 2011), a limited number of studies quantitatively estimated these impacts. This study reviewed information from these quantitative studies, identified gaps in knowledge and data, and provided recommendations for future studies.

\section{Climate change impacts}

\section{Actual climate changes}

Climate change include changes in greenhouse gas concentrations, temperature increase, precipitation pattern, extreme events and radiation. The increase in global surface temperature for the end of the $21^{\text {st }}$ century is likely to exceed $1.5^{\circ} \mathrm{C}$ to $4.5^{\circ} \mathrm{C}$, extremely unlikely to be less than $1{ }^{\circ} \mathrm{C}$, and very unlikely to be greater than $6{ }^{\circ} \mathrm{C}$ (Qin et al., 2013). Global warming increases the evaporation of water from land and ocean, and allows the atmosphere to hold more moisture. This change leads to more extreme precipitation. Annual mean precipitation is likely to increase by the end of this century in the high latitudes and tropical regions. In mid-latitude areas, arid regions will likely become drier and wet regions will likely become wetter. Extreme events will very likely become more frequent, more intense and of longer duration, and occasional cold winter extreme will continue to occur (Qin et al., 2013).

\section{Climate scenario development}

Scenario analysis is the central in all climate impacts research. In such analysis the climate change research community uses scenarios to improve understanding on how the future may be unfold based on what-if propositions. These scenarios include the complex interactions of the climate system, ecosystems, and human activities and conditions. The outputs of scenario analyses provide plausible descriptions of what may happen; they are not true predictions.

The Intergovernmental Panel on Climate Change (IPCC) has thus far provided four assessments of climate change and climate change impacts. The Third Assessment Report published in 2001 and the Fourth Assessment Report have used the so-called SRES scenarios (Special Report on Emission Scenarios (IPCC, 2000). These scenarios studied the uncertainty of future greenhouse gas and other pollutants emissions, assuming a wide range of driving forces, such as population growth, socio-economic development, etc.

Until now, the scenario analysis in IPCC followed a sequential approach. First of all, the SRES scenarios were set up and quantified. From this, the radiative forcing was calculated and then climate changes were estimated. The changes in climate variables were then used as inputs for impact models. The advantage of this approach is that coherent scenarios and storylines are obtained. However, the sequential approach was a slow process that took many years between emission and impact scenarios, and did not provide adequate opportunities for collaboration between physical, biological and social scientists. Therefore, the procedure for the Fifth Assessment Report of IPCC is following a fast parallel approach. For this approach, representative concentration pathways (RCPs) have been developed. Four typical pathways were selected. These lead to radiative forcing levels of $8.5 \mathrm{~W} / \mathrm{m}^{2}$ (business as usual), $6.0 \mathrm{~W} / \mathrm{m}^{2}$ (slowdown in emissions), $4.5 \mathrm{~W} / \mathrm{m}^{2}$ (mitigation) and $2.6 \mathrm{~W} / \mathrm{m}^{2}$ (strong mitigation) by the end of this century (Van Vuuren et al., 2011). The 'strong mitigation' RCP likely keeps climate change within the desired $2{ }^{\circ} \mathrm{C}$ target of the politically agreed Copenhagen Accords. The main advantages of the parallel approach are a reduced time period required to go through the full process and improved analysis of complex issues through improved collaboration between researchers that work on each part of the process (Moss et al., 2010).

Comparison of the carbon dioxide concentrations associated with the SRES and RCP future scenarios are summarised by Irving et al. (2012), Peters et al. (2013) and Knutti and Sedláček (2013). Among these future scenarios, SRES A1F1 (a scenario that describes very rapid economic growth, fast global population growth and technological emphasis on 
fossil fuel) and RCP 8.5 correspond to the highest level of $\mathrm{CO}_{2}$ concentrations and the strongest climate response. The overall range across the RCP scenarios is larger due to the inclusion of a low-emission mitigation scenario RCP 2.6. Knutti and Sedláček (2013) summarised that RCP projections seem largely consistent with SRES with a better process understanding.

\section{Application of climate scenarios}

Both the spatial (typically $200 \times 200 \mathrm{~km}$ ) and temporal (monthly or daily) resolution of the direct climate model outputs are much coarser than the detailed resolution of food safety impact models (Ramirez-Villegas and Challinor, 2012). This implies that these data underestimate temperature and precipitation extremes of actual field situation (Hofstra et al., 2010), and data thus need to be downscaled before they can be applied. Some general downscaling methods include the weather generator (Mearns et al., 1997; Van der Fels-Klerx et al., 2012b, 2013), bias correction (Hawkins et al., 2013; Huntingford et al., 2005; Ines and Hansen, 2006) and delta method (Arnell et al., 2003; Liu et al., 2015; Wilby et al., 2004).

\section{Climate change impacts on mycotoxins: expectations from theory}

\section{Mycotoxins and producing fungi}

Mycotoxins are produced by a wide variety of fungal species, each having their own characteristics and requirements for infection, growth and toxin production. Most important species for worldwide mycotoxin contamination of cereals and other crops are from the genus Aspergillus, Fusarium and Penicillium (Pitt, 2000). All mycotoxins regulated worldwide are produced by fungal species belonging to these mentioned genera. The attention is focused on most important mycotoxins, in terms of their presence and toxicity, including aflatoxins, ochratoxins, fumonisins, trichothecenes, and zearalenone (ZEA). Some species can produce more than one mycotoxin, and one particular mycotoxin can be produced by different species. Therefore, multimycotoxin contamination is expected in most products destined to human and animal consumption.

Aflatoxins are produced mainly by $A$. flavus and by Aspergillus parasiticus, and can be present in a variety of feed and food crops. Tropical and subtropical areas, between $40 \mathrm{~N}$ and $40 \mathrm{~S}$ latitude, are the most vulnerable to Aspergillus infection and aflatoxin contamination. Drought together with high temperatures increase aflatoxin production in field (Payne, 1998). Out of the four different aflatoxins $\left(B_{1}, B_{2}, G_{1}, G_{2}\right)$, aflatoxin $B_{1}\left(A F B_{1}\right)$ is the most predominant and has the highest toxicity. It has been classified by International Agency for Research on Cancer (IARC) as a known human carcinogen (IARC, 1993). Maize and nuts, peanuts and pistachio nuts, and cotton seeds give rise to main concern for aflatoxin contamination (Payne, 1998).

Ochratoxins are a group of related metabolites of which ochratoxin A (OTA) is the most common one. It has been classified by IARC as a possibly human carcinogen (IARC, 1993). Aspergillus ochraceus used to be considered the main OTA producer, particularly in cereals grown in warm climate. To date, other species of Aspergillus section Circumdati, Aspergillus steynii and Aspergillus westerdijkiae, are stated as the most important fungi for OTA production and related control and prevention strategies (Gil-Serna et al., 2015). Moreover, OTA can also be produced by several other Aspergillus spp., mainly belonging to section Nigri, crucial for grape contamination, and Penicillium species, e.g. Penicillium verrucosum, important for cereals grown in mild climates. The optimal temperature for Aspergillus ochraceus to produce ochratoxins is between 25 and $30{ }^{\circ} \mathrm{C}$ (Paterson and Lima, 2010; Sanchis and Magan, 2004). For $P$. verrucosum, the optimal temperature is $25^{\circ} \mathrm{C}$, but comparable contamination was detected at $15^{\circ} \mathrm{C}$ (Paterson and Lima, 2010; Sanchis and Magan, 2004). Due to the wide range of fungi able to produce OTA, this toxin has been reported from many different areas of the world, mainly in the currently temperate climates, in various food products. Typically, it is seen in cereals, coffee, cocoa, wine and beer.

Fumonisins are a group of mycotoxins mainly produced by members of Fusarium fujikuroi species complex, with Fusarium verticillioides as the prevalent and most studied species. Fumonisins are frequently detected in maize worldwide. A large number of fumonisins have been identified so far, but the $\mathrm{B}$ group (including $\mathrm{FB}_{1}$ to $\mathrm{FB}_{4}$ ) is the dominant one in food and feed commodities, with $\mathrm{FB}_{1}$ the most toxic, classified by IARC as a possibly human carcinogen. Related diseases vary in different animals, ranging from neurological to pulmonary and esophageal diseases (Desjardins, 2006). Ecological needs of $F$. verticillioides were deeply studied by several authors and they agree on maximum fumonisins production around $30{ }^{\circ} \mathrm{C}$, strongly influenced by water dynamic (Battilani et al., 2003, 2011; Marin et al., 1999).

Trichothecenes, mainly produced by various species of Fusarium, include deoxynivalenol (DON), nivalenol, 3 -and 15-acetyldeoxynivalenol, T-2 toxin, HT-2 toxin and diacetoxyscirpenol (Miller, 2002). These toxins are mainly found in cereals in almost all their growing areas around the world. DON is the prevalent trichothecene of concern in Europe (Miller, 2002). The optimal temperature for DON production ranges from 26 to $30{ }^{\circ} \mathrm{C}$ (Paterson and Lima, 2010). DON in food and feed can influence human and animal health with symptoms such as vomiting, anorexia, growth reduction, reproductive disorders, immunosuppression, etc. 
ZEA is mainly produced by Fusarium graminearum and related species (i.e. Fusarium culmorum) in cereals (Desjardins, 2006). Therefore, its presence is commonly related to DON production (Van der Fels-Klerx et al., 2012b). The contamination of food and animal feeds with ZEA is worldwide observed. Data on presence of ZEA in wheat, maize, barley, oat, soya meal, animal feed, beer, dried fruits and vegetables, sorghum, beets and rice from 34 countries are summarised by Zinedine et al. (2007). ZEA has oestrogenic and anabolic activity, and can cause infertility, abortion or other breeding problems, especially in swine (Kuiper-Goodman et al., 1987).

The geographic distribution of fungi reflects their ecological needs, with thermophilic fungi prevalent at lower latitudes and psychrophiles at the higher latitudes. A resulting gradient of mycotoxin contamination has been repeatedly stressed since early studies (Marasas et al., 1979) to recent year (Moretti and Logrieco, 2015). Care for details in fungal investigation is increasing, moving from identification of fungal species to phylogenetic species of clades and related mycotoxin chemotypes (Zhang et al., 2007). Risk maps, based on modelling and geostatistic approaches, were drawn for the presence of mycotoxins in wheat and maize (Battilani and Logrieco, 2014) and in grapes and nuts (Battilani et al., 2008) trying to depict a worldwide scenario.

Fungal species that can infect crops each have their own range of optimal environmental conditions - particularly related to temperature, rain and relative humidity - for crop infection, colonisation, toxin production and survival. Changes in climatic conditions will lead to shift in the fungal population and mycotoxin patterns. An interesting example can be based on maize, a suitable host crop for several mycotoxin producing fungi, including F. graminearum, Gibberella fujikuroi species complex (GFsc) and A. flavus. Based on the growing area, one of the mentioned fungi dominates and detected mycotoxins vary accordingly (Scudamore and Patel, 2000). In Europe, Fusarium spp. represent the matter of concern, with $F$. graminearum in the north and GFsc in the south. Only recently, since 2003, A. flavus has been recognised as an emerging problem in Europe (Piva et al., 2006).

In general, climate change is expected to increase mycotoxin contamination of crops (Marroquín-Cardona et al., 2014; Medina et al., 2014a,b; Miraglia et al., 2009; Paterson and Lima, 2010, 2011), but due to the complexity of mycoflora associated to each crop and its interaction with the environment, it appears rash to keep conclusions without specific studies. It is however sure that the pattern of mycotoxin distribution worldwide will change with climate change effects.

Many efforts have been devoted in developing models to predict mycotoxin contamination at harvest in several crops, with weather data as main or only input. Research focus was on Fusarium head blight in wheat, reviewed in Battilani and Logrieco (2014), with further recent contributes (Camardo Leggieri et al., 2013; Van der FelsKlerx et al., 2010, 2012c). Some attempts regarded also Fusaria (Van Asselt et al., 2012) and A. flavus (Battilani et al., 2013; Chauhan et al., 2015) in maize, while only few studies regard other toxins/crops, e.g. aflatoxins in peanuts (Chauhan et al., 2010) and OTA in grapes (Battilani and Camardo Leggieri, 2015a).

\section{Impact of climate change}

Climate change effects will influence fungal infections of crops and mycotoxin production of the earlier mentioned species in various ways, with many interacting effects. The most relevant climatic factors are believed to be temperature, humidity and precipitation (Battilani and Leggieri, 2015; Nazari et al., 2014; Shah et al., 2013; Van Asselt et al., 2012; Van Der Fels-Klerx et al., 2010). Those factors directly affect fungal infection and growth (Nazari et al., 2014). An increase of temperature in a certain area will thus directly affect the presence and the abundance of the species in crops grown in this area. More globally, the increase in average temperature in certain latitudes ranges will affect the species composition in this area. For instance, Aspergillus spp. typically is seen in tropical and subtropical regions in which high temperature and drought conditions occur. Until a decennia ago, these species were not observed in Europe, an area in the temperate zone. However, in Europe, increased occurrence of $A$. flavus and consequent aflatoxin contamination of maize has been seen since the 2000s (Medina et al., 2014a,b), coinciding with hot and dry summers. In 2003 and in 2008, outbreaks have been reported in Italy, and in 2013 a serious outbreak of aflatoxin contamination of maize occurred in the Balkan regions (De Rijk et al., 2015). Also in 2015 several non-compliances with legal limits in force in Europe for aflatoxins were reported in North Italy. However, summer in 2014 was mild and rainy, and relevant DON contamination was reported in the same geographic area, in contrast with data reported for the period of 2009-2011 (Camardo Leggieri et al., 2015). Support from predictive models could be very helpful in this context.

Climate change effects also have indirect impacts on mycotoxin contamination, e.g. related to increased drought stress and insect damage of the plant, and to changes in crop phenology, such as timing of flowering and maturing of cereals. For instance, maize is a crop whose susceptibility to A. flavus and GFsc infection is enhanced by drought stress and to insect damage, particularly Ostrinia nubilalis, the European corn borer (Mazzoni et al., 2011; Payne, 1998), all factors strongly dependent on climate. In this context, such a predictive modelling approach can include both direct and indirect impacts, and therefore provide 
a systematic support for all stakeholders (Battilani and Camardo Leggieri, 2015b).

\section{Climate change impacts on mycotoxins: modelling projections}

A couple of years ago, first quantitative estimations of climate change impacts on food safety have been made, applied to mycotoxin contamination of cereal grains. This issue was addressed in two different European research projects, focusing on different combinations of toxins-grain types: one study focused on DON concentrations in wheat produced in north west Europe (Van der Fels-Klerx et al., 2012b,c), whereas the other study focused on aflatoxin contamination of maize, wheat and rice grown in the whole Europe (Battilani et al., 2011, 2016). Both studies applied models of different disciplines including climate projection, crop phenology and fungal/mycotoxin prediction. These two studies were followed by a case study on Alternaria moulds and their mycotoxins in tomato (Van de Perre et al., 2015).

\section{EMTOX project}

The EMTOX project aimed to estimate the climate change impacts on DON contamination of wheat cultivated in North West Europe by 2040, using a modelling approach (Van der Fels-Klerx et al., 2012b,c). First, two empirical models were developed: one for estimating phenology of wheat grown in North West Europe (Olesen et al., 2012), and one for estimating DON contamination in wheat grown in North Western Europe (Van der Fels-Klerx et al., 2012a). The wheat phenology model estimates the various crop development stages, in particular flowering and full maturation, using climate data (Olesen et al., 2012). Both models were developed using a series of observed historical data. The model to predict DON in wheat used climate data as well as wheat phenology data as inputs to estimate DON concentrations in wheat grown in NW Europe. More specifically, input variables included wheat flowering date (ordinal date), length of period between flowering and full maturation (in days), wheat resistance class against Fusarium spp. (low/mid/high), and several climate variables related to relative humidity, temperature, and rainfall during critical wheat development stages (Van der Fels-Klerx et al., 2012a).

The EMTOX study used climate model projections for the future period 2031-2050 relative to the baseline period 1975-1994, based on the A1B SRES emission scenario. Climate model output from the ENSEMBLES project was used; this data can be downloaded from the ENSEMBLES database (http://ensemblesrt3.dmi.dk). Data included monthly temperature, precipitation, variability in temperature and duration of dry and wet series between the scenario and control periods of the climate model simulation runs (Madsen et al., 2012). Data from two (out of the 13) different combinations of global circulation models and regional climate models (GCM-RCM) were used, being the ones from KNMI (the Netherlands) and by METOHC (UK)), covering a reasonable range of patterns of projected temperature and rainfall. The LARS weather generator was used to produce series of 50 years of synthetic weather data (in the period 2031-2050), including daily precipitation, maximum and minimum temperature and solar radiation. The generated weather data, for each of the baseline, KNMI and METOHC scenarios, were used as inputs into the wheat phenology model. Next, the weather data and the phenology model outputs were both used as inputs for the DON prediction model. The climate data covered 50 simulations per grid, with 851 grids of $50 \times 50 \mathrm{~km}$ in total. Crop phenology and DON prediction models were run for each of spring wheat and winter wheat separately.

Results showed climate change was expected to result into a 1-2 weeks earlier of the median date of flowering and of full maturation of winter wheat, ranging up to about 26 days. Contamination of winter wheat with DON was, in general, expected to be increased in most of the study area with a factor two, incidentally up to a factor of four in some grids. For spring wheat, even more severe impacts were seen. However, variation between runs and between regions was large, and in some grids a decrease in DON levels was expected. A similar study for the Netherlands also predicted high spatial and annual variability of DON contamination in wheat in future climate (Van der FelsKlerx et al., 2013).

\section{MODMAP-AFLA project}

In the MODMAP-AFLA project, a modelling approach was used to predict future aflatoxin contamination of maize cultivated in Europe (Battilani et al., 2011, 2016). Three different IPCC climate change scenarios were used, including the present, $+2{ }^{\circ} \mathrm{C}$ (A2) and $+5{ }^{\circ} \mathrm{C}$ (B2) scenarios. Meteorological data, covering temperature, relative humidity and rainfall, were obtained from the LARS weather generator. This weather output was generated for 100 runs, from the period 2000-2100, on a $50 \times 50 \mathrm{~km}$ grid in Europe. These data were used as inputs for crop phenology estimation, and for the aflatoxin prediction model AFLA-maize. AFLA-maize is a mechanistic model for prediction of Aspergillus spp. infection and aflatoxin accumulation on a daily basis (Battilani et al., 2013). The outputs of this model, represented as an aflatoxin risk index (AFI), were linked to aflatoxin contamination, as observed in field studies.

A European database with mean daily temperature during maize emergence, flowering and harvesting was used to estimate, using the weather data, the shifts in maize flowering and harvesting in the three different climate 
scenarios. Results showed a reduction in the length of the cultivation season, and earlier flowering and harvest dates. This would lead to an enlargement of the area in Europe suitable for maize cultivation towards the Northern area. Weather data and estimated shifts in maize phenology were then fed into the AFLA-maize model, showing an expected increase of aflatoxin contamination of maize, mainly in the $+2{ }^{\circ} \mathrm{C}$ scenario. In this scenario, a particular increase in expected $A F B_{1}$ contamination was seen in the southern European countries, like centre and south of Spain, centre and south of Italy and the Balkans. In the $+5^{\circ} \mathrm{C}$ scenario, the area in Europe for which maize contamination was predicted was much higher than in the $+2^{\circ} \mathrm{C}$. However, estimated $\mathrm{AFB}_{1}$ contaminations were lower than in the $+2{ }^{\circ} \mathrm{C}$.

\section{Alternaria in tomato, a case study}

This study quantified the effect of increasing temperature on the mold growth and mycotoxin production on tomato using the new climate scenario analysis. The quantification has been done for the current, near (2031-2050) and far future (2081-2100). Four RCP scenarios (RCP2.6, RCP4.5, RCP6.0 and RCP8.5) were used in two tomato producing regions (Badajoz, Spain and Krobia, Poland). Daily minimum and maximum temperature data were gathered from the closest and most representative weather stations for the years 1981-2000. The coarse gridded data from the general circulation model HadGEM2-ES were selected and downscaled using the 'Delta method' with quantilequantile correction (Liu et al., 2015). In this way, coarse gridded data were downscaled to point (weather station) data. These daily data were further temporally downscaled to hourly data using a hyperbolic tangent function through minimum and maximum temperature (Schaub Jr., 1991). Then the temperature data were applied on the growth model of the Alternaria mold (Van de Perre et al., 2015).

The results showed that the impacts are region specific. For Spain, the temperatures in RCP 6.0 and 8.5 were projected too high $\left(18.2-38.2^{\circ} \mathrm{C}\right)$ for Alternaria spp. to grow, thus the diameter of the mould was calculated lower in the far future compared with the current time frame. For Poland, the projected temperatures become closer to the optimal temperature (14.2-28.4 ${ }^{\circ} \mathrm{C}$ ) for Alternaria spp. to grow. According to this study, the situation in Poland in the far future (2081-2100) is projected similar as the situation in Spain in the present time frame (1981-2000).

\section{Evaluating the three climate change studies}

Modelling the impact of climate change on the presence of mycotoxins has just started to get attention in the past years. To our knowledge, only these three case studies have focused on this topic so far, and demonstrated the methods of modelling mycotoxins using scenario analysis. The results of scenario analysis must always be interpreted carefully as plausible futures; they should not be considered precise predictions of the future. The processes to prepare and downscale climate data are based on what happened in the past. Because of this approach, they fail to correctly predict very extreme events. Then, due to the modelling approach, uncertainties are introduced, which consequently influence the results of impact assessment, such as mycotoxin prediction modelling.

Modelling mycotoxins needs to be done for each pathosystem (plant $\mathrm{x}$ fungus system) separately, and various approaches can be followed. Two different modelling approaches were used in the reported papers, empiric (EMTOX) and mechanistic (MODMAP-AFLA, Alternaria in tomato). Pros and cons can be highlighted in both modelling approaches, as discussed before (Camardo Leggieri et al., 2013; Van der Fels-Klerx and Booij, 2010). Empirical modelling is also defined as descriptive because mathematical functions are used to describe what was observed in field. Empirical models for mycotoxins can give a prediction for one point during cultivation, normally at harvest. They generally work well in limited geographic areas, while they need recalibration in conditions other than those from the data used for model calibration (e.g. wider geographical areas, other varieties). All cropping system parameters can be included in the model, in addition to weather data, if available for the field data used for model development. Mechanistic modelling is also defined as explanatory; it is based on system analysis, and considers the interaction between fungi and host crops. Each step of the fungal infection cycle is computed based on driving variables, with temperature, humidity and rain as mandatory input. These models thus can give daily output on fungal infection. Quantitative data are requested for each variable included in the model; this data often needs detailed experiments. It is, therefore, difficult to to include cropping system data. Mechanistic models generally work well with changing conditions, but also need to be validated for these changing conditions, since the environment influences the host-fungus system.

Two research gaps were identified in this review. First, the available predictive models for mycotoxins are validated in only one/few countries due to (limited) data availability and accessibility. This makes the possibility to use the empiric models for other European areas poorly robust. Input data from other regions are needed to extend predictions using current models or developing new models - to a wider areas. For extension of predictions of climate change impacts on mycotoxin occurrence based on empiric models to larger areas, the geographically oriented decision support system, proposed by Van der Fels-Klerx and Booij (2010), can be used as a starting point. This system can be adapted for modelling climate change impact on mycotoxin in a regional or continental level (Figure 1). With local climate 


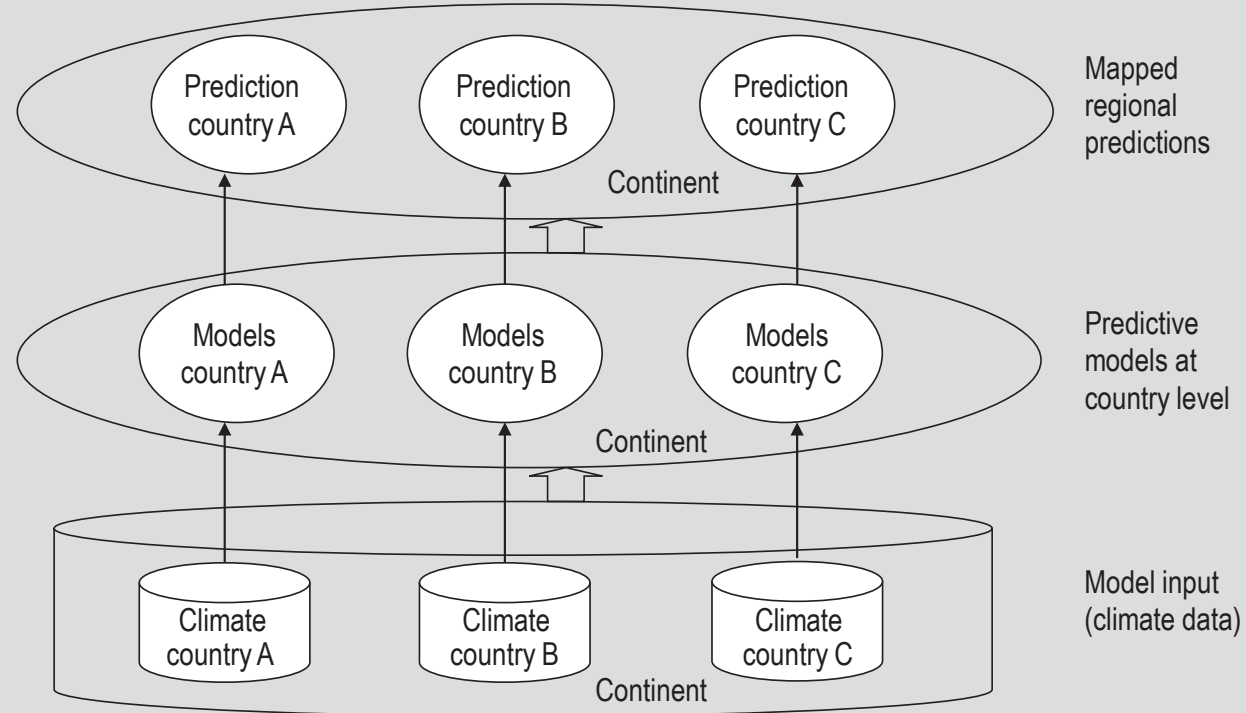

Figure 1. Geographically oriented modelling scheme for predicting impact of climate change on mycotoxin on a regional/continental scale (adapted from Van der Fels-Klerx and Booij, 2010).

data, predictive model from each country can compute the future crop phenology and the future mycotoxin level/ distribution due to climate change. Combining these models together will enable a broader overview of the region/ continent and keep the local accuracy at the same time. Such efforts are mandatory to be prepared for future changes and challenges related to mycotoxins. The second research gap identified in this review is that current climate change impact studies for mycotoxins focus on only some selected mycotoxin-crop combinations. The reason is the limited availability of predictive models for other combinations of mycotoxins-crops.

\section{Conclusions and recommendations}

Climate change will have an impact on food security, by its direct effects on yield and its indirect effects on food safety, as was recognised by FAO (2008). However, to date, research addressing possible climate change effects on food security has mainly focused on yields, rather than on the safety of the available food commodities. There is a need for quantitative estimations of projected climate change impacts on food safety, particularly mycotoxins in cereals and other crops. To date, only a very limited number of such quantitative studies have been done. To our knowledge, only three quantitative modelling approaches for impacts of climate change effects on mycotoxins were published, as we reviewed in this paper, all focused on Europe.

This review identified two research gaps. First, the available predictive models for mycotoxins are validated in only one/few countries due to (limited) data availability and accessibility. Second, current climate change impact studies for mycotoxins focus on some selected mycotoxincrop combinations only. Predictive models for other combinations of mycotoxins-crops are needed to be able to better assist mycotoxin management during crop cultivation in Europe, and to mitigate the expected climate change impacts on mycotoxins.

Overall, the approach taken into the three recent studies showed to be promising. Such a quantitative and integrative approach for estimating impacts of climate change on food safety could also be taken for other food safety hazards and production systems, such to obtain a more comprehensive view on the consequences of climate change for food safety.

\section{References}

Arnell, N., Hudson, D. and Jones, R., 2003. Climate change scenarios from a regional climate model: estimating change in runoff in southern Africa. Journal of Geophysical Research: Atmospheres 108: 4519.

Battilani, P. and Camardo Leggieri, M., 2015a. OTA-grapes: a mechanistic model to predict ochratoxin A risk in grapes, a step beyond the systems approach. Toxins 7: 3012-3029.

Battilani, P. and Camardo Leggieri, M., 2015b. Predictive modelling of aflatoxin contamination to support maize chain management. World Mycotoxin Journal 8: 161-170.

Battilani, P. and Leggieri, M.C., 2015. Predictive modelling of aflatoxin contamination to support maize chain management. World Mycotoxin Journal 8: 161-170.

Battilani, P. and Logrieco, A., 2014. Global risk maps for mycotoxins in wheat and maize. In: Leslie, J. and Logrieco, A., 2014. Mycotoxin reduction in grain chains: a practical guide Wiley-Blackwell, Oxford, UK, pp. 309-326. 
Battilani, P., Barbano, C. and Logrieco, A., 2008. Risk assessment and safety evaluation of mycotoxins in fruits. In: Barkai-Golan, R. and Pastor, N. (eds.) Mycotoxins in fruits and vegetables. Elsevier, Amsterdam, the Netherlands, pp. 1-26.

Battilani, P., Camardo Leggieri, M., Rossi, V. and Giorni, P., 2013. AFLA-maize, a mechanistic model for Aspergillus flavus infection and aflatoxin $\mathrm{B}_{1}$ contamination in maize. Computer and Electronics in Agriculture 94: 38-46.

Battilani, P., Formenti, S., Rossi, V. and Ramponi, C., 2011. Dynamic of water activity in maize hybrids is crucial for fumonisin contamination in kernels. Journal of Cereal Science 54: 467-472.

Battilani, P., Rossi, V. and Pietri, A., 2003. Modelling Fusarium verticillioides infection and fumonisin synthesis in maize ears. Aspects of Applied Biology 68: 91-100.

Battilani, P., Rossi, V., Giorni, P., Pietri, A., Gualla, A., Van der Fels-Klerx, H.J., Booij, C.J.H., Moretti, A., Logrieco, A., Toscano, P., Miraglia, M., De Santis, B. and Brera, C., 2012. Modelling, predicting and mapping the emergence of aflatoxins in cereals in the EU due to climate change. Scientific/Technical Report submitted to EFSA. Available at: http://www.efsa.europa.eu/en/supporting/pub/223e.htm.

Battilani, P., Toscano, P., Van der Fels-Klerx, H.J., Moretti, A., Camardo Leggieri, M., Brera, C., Rortais, A., Goumperis, T. and Robinson, T., 2016. Aflatoxin $B_{1}$ contamination in maize in Europe increases due to climate change. Scientific Reports 6 DOI: https://doi.org/10.1038/ srep24328.

Bindi, M. and Olesen, J.E., 2011. The responses of agriculture in Europe to climate change. Regional Environmental Change 11: 151-158.

Camardo Leggieri, M., Bertuzzi, T., Pietri, A. and Battilani, P., 2015. Mycotoxin occurrence in Italian maize produced in 2009-2011 and focus on the role of crop related factors. Phytopathologia Mediterranea 54: 212-221.

Camardo Leggieri, M., Van Der Fels-Klerx, H.J. and Battilani, P., 2013. Cross-validation of predictive models for occurrence of deoxynivalenol in wheat at harvest. World Mycotoxin Journal 6: 389-397.

Chauhan, Y.S., Tatnell, J., Krosch, S., Karanja, J., Gnonlonfin, B., Wanjuki, I., Wainaina, J. And Harvey, J., 2015. An improved simulation model to predict pre-harvest aflatoxin risk in maize. Field Crops Research 178: 91-99.

Chauhan, Y.S., Wright, G.C., Rachaputi, R.C.N., Holzworth, D., Broome, A., Krosch, S. and Robertson, M.J., 2010. Application of a model to assess aflatoxin risk in peanuts. Journal of Agricultural Science 48: 341-335.

De Rijk, T., Van Egmond, H., Van der Fels-Klerx, H., Herbes, R., De Nijs, M., Samson, R., Slate, A. and Van der Spiegel, M., 2015. A study of the 2013 Western European issue of aflatoxin contamination of maize from the Balkan area. World Mycotoxin Journal 8: 641-651.

Desjardins, A.E., 2006. Fusarium mycotoxins. Chemistry, genetics, and biology, American Phytopathological Society Press, St. Paul, MN, USA.

European Commission (EC), 2009. Adapting to climate change: towards a European framework for action. White paper COM (2009) 147. Available at: http://tinyurl.com/hj7d9df.
Ewert, F., Rounsevell, M., Reginster, I., Metzger, M. and Leemans, R., 2005. Future scenarios of European agricultural land use: I. Estimating changes in crop productivity. Agriculture, Ecosystems and Environment 107: 101-116.

Falloon, P. and Betts, R., 2010. Climate impacts on European agriculture and water management in the context of adaptation and mitigation - the importance of an integrated approach. Science of the Total Environment 408: 5667-5687.

Field, C.B., 2012. Managing the risks of extreme events and disasters to advance climate change adaptation: special report of the intergovernmental panel on climate change. Cambridge University Press, Cambridge, UK.

Food and Agriculture Organization (FAO), 2008a. Climate-related transboundary pests and diseases. FAO, Rome, Italy.

Food and Agriculture Organization (FAO), 2008b. Climate change: implications for food safety. FAO, Rome, Italy.

Gil-Serna, J., Patiño, B., Cortes, L., Gonzalez-Jaen, M.T. and Vazquez, C., 2015. Aspergillus steynii and Aspergillus westerdijkiae as potential risk of OTA contamination in food products in warm climates. Food Microbiology 46: 168-175.

Giorni, P., Magan, N., Pietri, A., Bertuzzi, T. and Battilani, P., 2007. Studies on Aspergillus section Flavi isolated from maize in northern Italy. International Journal of Food Microbiology 113: 330-338.

Gregory, P.J., Ingram, J.S. and Brklacich, M., 2005. Climate change and food security. Philosophical Transactions of the Royal Society of London B: Biological Sciences 360: 2139-2148.

Gregory, P.J., Johnson, S.N., Newton, A.C. and Ingram, J.S., 2009. Integrating pests and pathogens into the climate change/food security debate. Journal of Experimental Botany 60: 2827-2838.

Hawkins, E., Osborne, T.M., Ho, C.K. and Challinor, A.J., 2013. Calibration and bias correction of climate projections for crop modelling: an idealised case study over Europe. Agricultural and Forest Meteorology 170: 19-31.

Hofstra, N., New, M. and McSweeney, C., 2010. The influence of interpolation and station network density on the distributions and trends of climate variables in gridded daily data. Climate Dynamics 35: 841-858.

Huntingford, C., Lambert, F.H., Gash, J.H., Taylor, C.M. and Challinor, A.J., 2005. Aspects of climate change prediction relevant to crop productivity. Philosophical Transactions of the Royal Society of London B: Biological Sciences 360: 1999-2009.

Ines, A.V. and Hansen, J.W., 2006. Bias correction of daily GCM rainfall for crop simulation studies. Agricultural and Forest Meteorology 138: 44-53.

Intergovernmental Panel on Climate Change (IPCC), 2000. Special report on emissions scenarios: a special report of Working Group III of the IPCC. Cambridge University Press, Cambridge, UK.

Intergovernmental Panel on Climate Change (IPCC), 2007. Climate change 2007: the physical science basis. IPCC, Cambridge, UK.

International Agency for Research on Cancer (IARC), 1993. Some naturally occurring substances: food items and constituents, heterocyclic aromatic amines and mycotoxins. IARC Monographs on the evaluation of carcinogenic risks to humans. Vol. 56. IARC, Lyon, France. 
Irving, D.B., Whetton, P. and Moise, A.F., 2012. Climate projections for Australia: a first glance at CMIP5. Australian Meteorological and Oceanographic Journal 62: 211-225.

Knutti, R. and Sedláček, J., 2013. Robustness and uncertainties in the new CMIP5 climate model projections. Nature Climate Change 3: 369-373.

Kuiper-Goodman, T., Scott, P. and Watanabe, H., 1987. Risk assessment of the mycotoxin zearalenone. Regulatory Toxicology and Pharmacology 7: 253-306.

Liu, C., Hofstra, N. and Franz, E., 2013. Impacts of climate change on the microbial safety of pre-harvest leafy green vegetables as indicated by Escherichia coli $\mathrm{O} 157$ and Salmonella spp. International Journal of Food Microbiology 163: 119-128.

Liu, C., Hofstra, N. and Leemans, R., 2015. Preparing suitable climate scenario data to assess impacts on local food safety. Food Research International 68: 31-40.

Lobell, D.B., Burke, M.B., Tebaldi, C., Mastrandrea, M.D., Falcon, W.P. and Naylor, R.L., 2008. Prioritizing climate change adaptation needs for food security in 2030. Science 319: 607-610.

Madgwick, J.W., West, J.S., White, R.P., Semenov, M.A., Townsend, J.A., Turner, J.A. and Fitt, B.D., 2011. Impacts of climate change on wheat anthesis and Fusarium ear blight in the UK. European Journal of Plant Pathology 130: 117-131.

Madsen, M.S., Fox Maule, C., MacKellar, N., Olesen, J.E. and Christensen, J.H., 2012. Selection of climate change scenario data for impact modelling. Food Additives and Contaminants Part A 29: 1502-1513.

Magan, N., Medina, A. and Aldred, D., 2011. Possible climatechange effects on mycotoxin contamination of food crops pre- and postharvest. Plant Pathology 60: 150-163.

Marasas, W.F.O., Kriek, N.P.J., Wiggins, V.M., Steyn, P.S., Towers, D.K. and Hastie, T.J., 1979. Incidence, geographic distribution, and toxigenicity of Fusarium species in South African corn. Phytopathology 69: 1181-1185.

Marín, P., De Ory, A., Cruz, A., Magan, N. and González-Jaén, M.T., 2013. Potential effects of environmental conditions on the efficiency of the antifungal tebuconazole controlling Fusarium verticillioides and Fusarium proliferatum growth rate and fumonisin biosynthesis. International Journal of Food Microbiology 165: 251-258.

Marroquín-Cardona, A., Johnson, N., Phillips, T. and Hayes, A., 2014. Mycotoxins in a changing global environment - a review. Food and Chemical Toxicology 69: 220-230.

Marvin, H.J., Kleter, G.A., Noordam, M.Y., Franz, E., Willems, D.J. and Boxall, A., 2013. Proactive systems for early warning of potential impacts of natural disasters on food safety: climate-change-induced extreme events as case in point. Food Control 34: 444-456.

Mazzoni, E., Scandolara, A., Giorni, P., Pietri, A. and Battilani, P., 2011. Field control of Fusarium ear rot, Ostrinia nubilalis (Hübner) and fumonisins in maize kernels. Pest Management Science 67: 458-465.

Mearns, L.O., Rosenzweig, C. and Goldberg, R., 1997. Mean and variance change in climate scenarios: methods, agricultural applications, and measures of uncertainty. Climatic Change 35: 367-396.
Medina A., Rodriguez A. and Magan, N., 2014a. Effect of climate change on Aspergillus flavus and aflatoxin $\mathrm{B}_{1}$ production. Frontiers in Microbiology 5: 348. Available at: http://doi.org/10.3389/ fmicb.2014.00348.

Medina, A., Rodríguez, A., Sultan, Y. and Magan, N., 2014b. Climate change factors and Aspergillus flavus: effects on gene expression, growth and aflatoxin production. World Mycotoxin Journal 8: 171-179.

Miller, J.D., 2002. Aspects of the ecology of Fusarium toxins in cereals. In: DeVries, J.W., Trucksess, M.W. and Jackson, L.S. (eds.) Mycotoxins and food safety. Springer, Washington, DC, USA, pp. 19-27.

Miraglia, M., De Santis, B. and Brera, C., 2008. Climate change: implications for mycotoxin contamination of foods. Journal of Biotechnology 136: S715.

Miraglia, M., Marvin, H., Kleter, G., Battilani, P., Brera, C., Coni, E., Cubadda, F., Croci, L., De Santis, B. and Dekkers, S., 2009. Climate change and food safety: an emerging issue with special focus on Europe. Food and Chemical Toxicology 47: 1009-1021.

Moss, R.H., Edmonds, J.A., Hibbard, K.A., Manning, M.R., Rose, S.K., Van Vuuren, D.P., Carter, T.R., Emori, S., Kainuma, M. and Kram, T., 2010. The next generation of scenarios for climate change research and assessment. Nature 463: 747-756.

Nazari, L., Pattori, E., Terzi, V., Morcia, C. and Rossi, V., 2014. Influence of temperature on infection, growth, and mycotoxin production by Fusarium langsethiae and F. sporotrichioides in durum wheat. Food Microbiology 39: 19-26.

Olesen, J.E., Børgesen, C.D., Elsgaard, L., Palosuo, T., Rötter, R., Skjelvåg, A., Peltonen-Sainio, P., Börjesson, T., Trnka, M. and Ewert, F., 2012. Changes in time of sowing, flowering and maturity of cereals in Europe under climate change. Food Additives and Contaminants Part A 29: 1527-1542.

Olesen, J.E., Carter, T., Diaz-Ambrona, C., Fronzek, S., Heidmann, T., Hickler, T., Holt, T., Minguez, M., Morales, P. and Palutikof, J., 2007. Uncertainties in projected impacts of climate change on European agriculture and terrestrial ecosystems based on scenarios from regional climate models. Climatic Change 81: 123-143.

Ongoma, V., 2013. A review of the effects of climate change on occurrence of aflatoxin and its impacts on food security in semiarid areas of Kenya. International Journal of Scientific Research in Agricultural Sciences 2: 307-311.

Pachauri, R.K. and Reisinger, A., 2007. Climate change 2007 synthesis report: summary for policymakers. IPCC Secretariat, Cambridge, UK.

Paterson, R.R.M. and Lima, N., 2011. Further mycotoxin effects from climate change. Food Research International 44: 2555-2566.

Paterson, R.R.M. and Lima, N., 2010. How will climate change affect mycotoxins in food? Food Research International 43: 1902-1914.

Paterson, R.R.M., Lima, N. and Taniwaki, M.H., 2014. Coffee, mycotoxins and climate change. Food Research International 61: 1-15.

Payne, G.A., 1998. Process of contamination by aflatoxin-producing fungi and their impact on crops. In: Sinha, K.K. and Bahtnagar, D. (eds.) Mycotoxins in agriculture and food safety. Marcel Dekker, new York, NY, USA, pp. 279-306. 
Peters, G.P., Andrew, R.M., Boden, T., Canadell, J.G., Ciais, P., Le Quere, C., Marland, G., Raupach, M.R. and Wilson, C., 2013. The challenge to keep global warming below $2{ }^{\circ} \mathrm{C}$. Nature Climate Change 3: 4-6.

Pitt, J., 2000. Toxigenic fungi and mycotoxins. British Medical Bulletin 56: 184-192.

Piva, G., Battilani, P. and Pietri, A., 2006. Emerging issues in Southern Europe: aflatoxins in Italy. In: Barug, D., Bhatnagar, D., Van Egmond, H.P., Van der Kamp, J.W., Van Osenbruggen, W.A. and Visconti, A. (eds.) The mycotoxin factbook. Wageningen Academic Publishers, Wageningen, the Netherlands, pp. 139-153.

Qin, D., Plattner, G., Tignor, M., Allen, S., Boschung, J., Nauels, A., Xia, Y., Bex, V. and Midgley, P., 2013. Summary for policymakers. Climate change 2013: the physical science basis. Contribution of Working Group I to the fifth assessment report of the Intergovernmental Panel on Climate Change. Cambridge University Press, Cambridge, UK.

Ramirez-Villegas, J. and Challinor, A., 2012. Assessing relevant climate data for agricultural applications. Agricultural and Forest Meteorology 161: 26-45.

Sanchis, V. and Magan, N., 2004. Environmental conditions affecting mycotoxins. In: Magan, N. and Olsen, M. (eds.) Mycotoxins in food, detection and control. Woodhead Publishing, Abington, UK, pp. 174-189.

Schaub Jr., W.R., 1991. A method for estimating missing hourly temperatures using daily maximum and minimum temperatures. DTIC Document. USAF Environmental Technical Applications Center, Scott Air Force Base, IL, USA. Available at: http://tinyurl. com/hh4nk82.

Scudamore, K.A. and Patel, S., 2000. Survey for aflatoxins, ochratoxin $A$, zearalenone and fumonisins in maize imported into the United Kingdom. Food Additives and Contaminants 17: 407-416.

Shah, D., Molineros, J., Paul, P., Willyerd, K., Madden, L. and De Wolf, E.D., 2013. Predicting Fusarium head blight epidemics with weather-driven pre-and post-anthesis logistic regression models. Phytopathology 103: 906-919.

Tirado, M., Clarke, R., Jaykus, L.-A., McQuatters-Gollop, A. and Frank, J., 2010. Climate change and food safety: a review. Food Research International 43: 1745-1765.

Trnka, M., Muška, F., Semerádová, D., Dubrovský, M., Kocmánková, E. and Žalud, Z., 2007. European corn borer life stage model: regional estimates of pest development and spatial distribution under present and future climate. Ecological Modelling 207: 61-84.

Van Asselt, E.D., Booij, C.J.H. and Van der Fels-Klerx, H.J., 2012. Modelling mycotoxin formation by Fusarium graminearum in maize in the Netherlands. Food Additives and Contaminants Part A 29: 1572-1580.
Van de Perre, E., Jacxsens, L., Liu, C., Devlieghere, F. and De Meulenaer, B., 2015. Climate impact on Alternaria moulds and their mycotoxins in fresh produce: the case of the tomato chain. Food Research International 68: 41-46.

Van der Fels-Klerx, H. and Booij, C., 2010. Perspectives for geographically oriented management of Fusarium mycotoxins in the cereal supply chain. Journal of Food Protection 73: 1153-1159.

Van der Fels-Klerx, H., Burgers, S.L. and Booij, C., 2010. Descriptive modelling to predict deoxynivalenol in winter wheat in the Netherlands. Food Additives and Contaminants Part A 27: 636-643.

Van der Fels-Klerx, H., Goedhart, P., Elen, O., Börjesson, T., Hietaniemi, V. and Booij, C., 2012a. Modeling deoxynivalenol contamination of wheat in northwestern Europe for climate change assessments. Journal of Food Protection 75: 1099-1106.

Van der Fels-Klerx, H., Olesen, J.E., Madsen, M. and Goedhart, P., 2012b. Climate change increases deoxynivalenol contamination of wheat in north-western Europe. Food Additives and Contaminants Part A 29: 1593-1604.

Van der Fels-Klerx, H., Olesen, J.E., Naustvoll, L.-J., Friocourt, Y., Mengelers, M. and Christensen, J., 2012c. Climate change impacts on natural toxins in food production systems, exemplified by deoxynivalenol in wheat and diarrhetic shellfish toxins. Food Additives and Contaminants Part A 29: 1647-1659.

Van der Fels-Klerx, H., Van Asselt, E.D., Madsen, M.S. and Olesen, J.E., 2013. Impact of climate change effects on contamination of cereal grains with deoxynivalenol. PloS One 8: e73602.

Van Vuuren, D.P., Edmonds, J., Kainuma, M., Riahi, K., Thomson, A., Hibbard, K., Hurtt, G.C., Kram, T., Krey, V. and Lamarque, J.-F., 2011. The representative concentration pathways: an overview. Climatic Change 109: 5-31.

Wheeler, T. and Von Braun, J., 2013. Climate change impacts on global food security. Science 341: 508-513.

Wilby, R., Charles, S., Zorita, E., Timbal, B., Whetton, P. and Mearns, L., 2004. Guidelines for use of climate scenarios developed from statistical downscaling methods. Intergovernmental Panel on Climate Change, Cambridge, UK.

Wu, F., Bhatnagar, D., Bui-Klimke, T., Carbone, I., Hellmich, R., Munkvold, G., Paul, P., Payne, G. and Takle, E., 2011. Climate change impacts on mycotoxin risks in US maize. World Mycotoxin Journal 4: 79-93.

Zinedine, A., Soriano, J.M., Molto, J.C. and Manes, J., 2007. Review on the toxicity, occurrence, metabolism, detoxification, regulations and intake of zearalenone: an oestrogenic mycotoxin. Food and Chemical Toxicology 45: 1-18. 